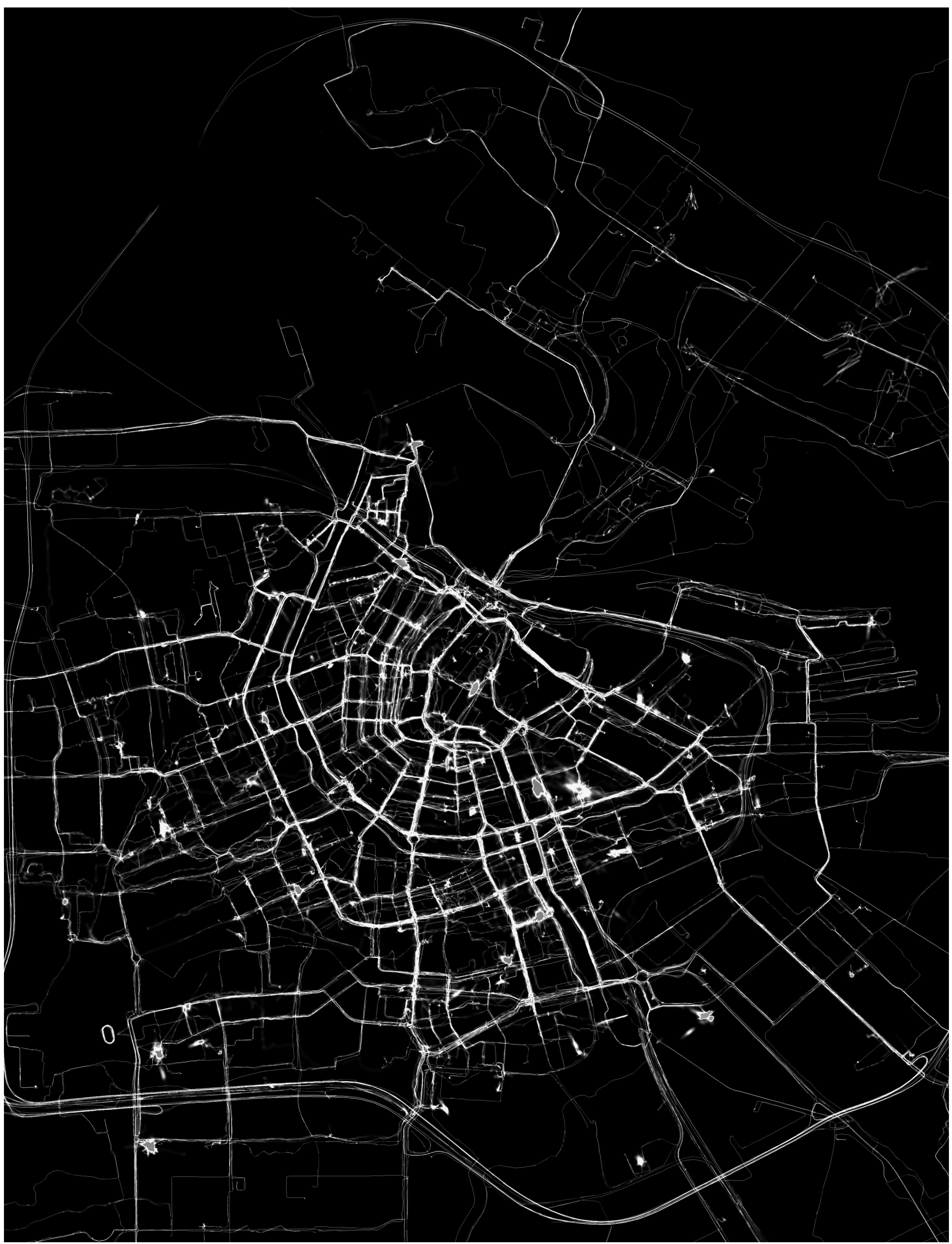




\section{Locative Arts}

\section{Drew Hemment}

\begin{abstract}
The artist: the first person to set out a boundary stone, or to make a mark
\end{abstract}

_Gilles Deleuze and Felix Guattari [1]

When the oceans became navigable following the deployment of the chronometer as an onboard location device, our view of the earth and our relationship to it changed, as did the forms of representation used to express or explore that relationship. The first photographs from the Apollo space missions changed once more the view of the earth and yielded one of the most iconic and ubiquitous images ever produced. Today it is digital and satellite mapping technologies that have caught the attention of a new generation of artists and do-ityourself (DIY) technologists, who are exploring the use of portable, networked, location-aware computing devices for user-led mapping, social networking and artistic interventions in which the fabric of the urban environment and the contours of the earth become a "canvas" [2].

All art engages in location to some degree, even if just in the way that it responds to the space created by gallery and frame, or the way that the found object is marked by the absence of the location from which it was drawn. If a precursor to locative media were to be identified within the art world, it might be the work of Richard Long, who creates his art by walking through a landscape, annotating the physical environment he encounters with stones or other ambient materials, and documenting this augmented space, creating photographs that provide an esoteric other to the objectifying gaze of cartography or satellite photography.

If net art is the art of the Internet, then locative art is the art of mobile and wireless systems [3]. The emergence of locative media signals a convergence of geographical and data space that comes about as soon as computing becomes mobile or ambient, reversing the trend toward the view of digital content as placeless, only encountered in the amorphous and other space of the Internet [4]. The exploratory movements of locative art are located between the art of communications and networking and the arts of landscape, walking and the environment. Artists are responding to the technical possibilities of electronic mapping and positioning technologies and location-aware, networked media by asking what can be ex-

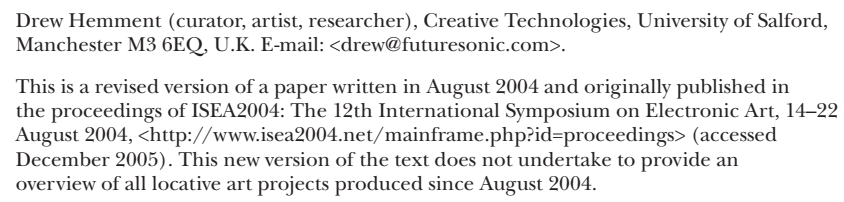

Article Frontispiece. Esther Polak, Amsterdam Realtime project, GPS visualization, 2003. (Photo @ Esther Polak/WAAG Society) perienced now that could not be experienced before, in some cases creating more or less conventional screen-based visualizations using location data, in others mapping new horizons for creative content and the art object and a new understanding of the relation between physical and digital.

Locative art and locative media are less focused on positioning than on the preconditions of moving or being able to move. This paper is likewise concerned with the preconditions for a locative art rather than with a set of current projects or artifacts. It is specifically concerned with the period between 2003 and 2004 [5]. At that time locative media was in an embryonic state, everything still up for grabs; a zone of consistency was yet to emerge. While artists such as Masaki Fujihata (Japan), Teri Rueb (U.S.A.), Stefan Schemat (Germany) and Iain Mott (Australia) had for many years been producing work we may term locative art, in this period locative media and locative art were simultaneously opening up new ways of engaging in the world and mapping their own domain. This resonates with Deleuze and Guattari's sense of territory, in which there is a blurring of the distinction between real estate and intellectual property, between the mapping of physical space and the production of an artistic or cultural milieu: the territory is constituted by the signature or expressive mark, both in the sense that birds use song to map their domain and that the artist creates a new way of seeing and occupying the world.

\section{A TAXonomy OF Locative ARTS}

A focus on this period enables us to study the stem cells of locative media and locative arts and thus refuse a narrow understanding of locative media that has since emerged. A classification of locative art projects that is useful for initial orientation might include the categories mapping, geoannotation and ambulant (walking or moving about).

\section{Mapping}

Digital mapping is at the core of many locative projects, and there is a vibrant area of locative media that defines itself primarily as a grassroots, open version of GIS (Geographic Information Systems).

Open and Wiki Maps. One approach that has become common is to generate line drawings from global positioning system (GPS) data generated by people moving through the physical environment. One such set of images was produced 


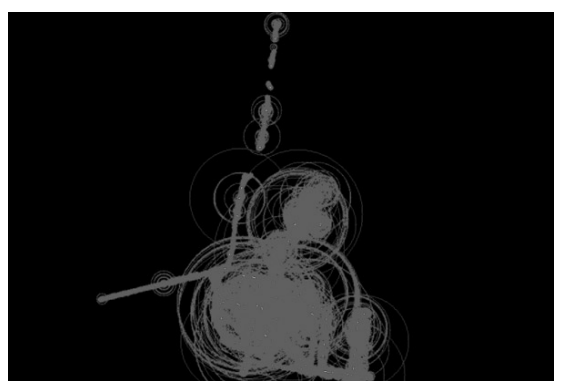

Fig. 1. RIXC, GPS visualization at Locative Media Workshop in Karosta, Latvia, 2003; screen grab from <http://locative.x-i.net/>. (ㄷ) Raitis Smits)

at an influential workshop at Karosta in Latvia, hosted by the media art collective RIXC-an event that brought together many early practitioners and played an important role in the emergence of the field of locative media [6]. The basic cartographic technique of generated line drawings enables the creation of digital maps that are not dependent upon any previously existing data set, such as U.K. Ordinance Survey (OS) data. This makes possible user-generated, editable maps that work on the same "open" principles as those behind projects such as Wikipedia, where content is generated and maintained by the users. With such "wikimaps" it is not just individual landmarks that are created and maintained by users, but the features of the landscape and geographical information as well.

In Amsterdam RealTime, by Ester Polak (the Netherlands), an early, seminal locative-media piece, participants roamed the streets of Amsterdam equipped with networked GPS devices, and traces of their movements were relayed to a projection screen in an exhibition space (Article Frontispiece). At the outset the screen is blank, but as the journeys are recorded, individual meanderings fuse into a composite representation of how people occupy and use the city-density and concentration are recorded in the luminescence of overlapping lines; spaces unvisited remain dark. While, as Eric Kluitenberg pointed out during the ISEA2004 conference, such composite images generated through successive superimpositions are statistical in nature, the project offers an evocative visual portrait of the life of the city and a grassroots, collaborative mapping of how urban space is used that offers an alternative to the top-down perspective of conventional cartography.

Figurative, Expressive, Performative. GPS Drawing, by Jeremy Wood (U.K.), uses this same technique to create not re- alistic representations of a town or terrain but outline images of animals, symbols and words, shifting the focus from realism or documentation to figurative drawing. One example is what Wood describes as "the world's biggest IF," stretching from the south coast of England to East Anglia-an outline drawing of the word IF created by positional data generated during a journey across the country and then superimposed over a satellite photograph of the U.K.

The Karosta images illustrate a visual aesthetic common to many such GPS projects, where expression emerges between the cartographic contours in the intricate abstract shapes produced through this mapping technique. Some involve a secondary mapping of error, plotting the accuracy of each GPS reading as the diameter of a circle, generating aleatory tracings that expose the limit of the technical system (Fig. 1) [7]. Artists have explored this aesthetic in a variety of ways, such as the use of rope and string in the Distance Made Good gallery-based installations by Jen Hamilton and Jen Southern (Canada/U.K.).

In projects where mapping and tracking techniques are applied in an art context, the participants tend to have a different relationship to the data or artifacts produced than would otherwise be the case, and this often takes on a performative aspect. A number of locative art projects involve performance or performers, such as Myriorama, by AmbientTV.NET (U.K.), and Choreography of Everyday Movement, by Teri Rueb (U.S.A.). Many more feature some element of performance by non-performers, whether this be the filmmaker Pete Gomes drawing in chalk outside the ICA in London or the participants in Fujihata's FieldWorks pirouetting playfully while making impromptu sketches. What is of note here is the way in which awareness that movement is being recorded or mapped,

Fig. 2. InterUrban, Untitled (Jeff and visitor downtown LA), 2003. (Photo @ L. Naomi Spellmann)

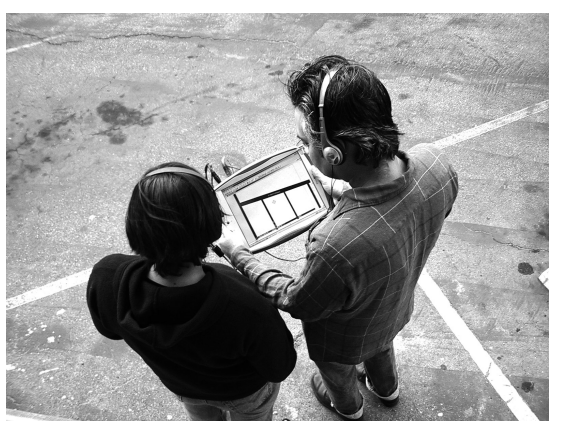

even if this be abstracted to just a line or dot, affects the way people act and move in the present.

Social, Semantic. Much current interest is concerned with the interface between locative media and social software, the semantic web or web 2.0. Such maps can be combined with calendar tools or with social software so that users are "able to find things-events/pictures / anything-'near' to them, where 'near' can mean close in geographical location, in 'person space,' or in 'interest space"' [8]. Metaphors such as "a programmable and machine-readable world," "people search engines," "social interfaces to places," "city as canvas or medium" and "person as cursor in the city" abound. There is a strong current of social projects within locative media, and a DIY technology culture has grown around it as part of a wider space that includes copyleft, open source, free networking, etc. In an arts context, mobile social networking and social network analysis have been explored in the work Trace Encounters. Infrared pins given to the audience at Ars Electronica 2004 detected and recorded any other pin that passed within range. The connections between pins, and-by implication-people, were visualized in the gallery to display "cliques" and shared patterns of movement (of a similar kind to those explored in the $\mathrm{Fa}$ miliar Strangers project).

\section{Geo-Annotation}

"Geo-annotation" is a central concept within locative media and is here understood as making data geographically specific or placing a digital object in space. Geo-annotation involves authoring media in an environment and accessing it at that same location. Media contents-digital photos, for example-are assigned spatial coordinates, recording the place at which they were taken as metadata (data about data), in the same way that time and date are stored. These photos may be accessed by an enabled device, configured to select digital objects whose spatial attributes correspond with the device's current location. While the "true" location of the content is a database, by making it possible to access that content in a particular position-and only in that position-its place migrates into the physical environment. Whether the user is authoring or only accessing content, the metaphor remains: The person becomes a kind of "cursor" navigating digital media located in the world.

Located Media. Geo-annotation has generated widespread interest for use in 
everything from museum or city guides to utility-company field operations. Here it is used as a means of documentation and of augmenting the environment with additional information that elaborates or explains something already present. It is another means of delivering information, a new way of experiencing otherwise conventional media content in the environment.

Graffiti, Narrative, Gaming. Geograffiti (Canada/U.K.) and GeoNotes (Sweden) seek not to document or interpret the environment, but instead to embellish it with digital graffiti or virtual tagging as expressive mark. The same basic principle is at play in InterUrban (U.S.A.), but in this case, multiple, interconnected digital contents create an ambient narrative, experienced via movement through an urban space and encounters with narrative elements designed to make sense in any sequence (Fig. 2). Likewise Uncle Roy All Around You, by Blast Theory and the Mixed Reality Lab (U.K.), combines ambient narrative with pervasive game play.

Social Authoring. In a number of projects the focus is on opening up a social space by enabling people to produce their own content within such an environment. (area)code (U.K.) and [murmur] (Canada) enable people to author and access stories, poems or anecdotes about a particular place via a mobile phone using SMS (short-message service) or voice mail, respectively, not by using digital positioning technology but simply by advertising an access number on posters located in designated sites. Yellow Arrow (U.S.A.) adopts a similar low-tech approach, but in this case uses stickers so that participants, rather than the project creators, can choose where the digital object is placed as well as its content, enabling it to work on a much larger scale without ties to any one particular site. $U r$ ban Tapestries (U.K.) and Mobile Bristol (U.K.) are more complex locative authoring platforms. They have been the focus of social experimentation that explores how multiple layers or threads of meaning may be woven or inserted within the environment in a form of collaborative authoring characterized by multiplication, as well as localization, of perspective. In these kinds of projects it starts to become possible for users to engage with the database rather than just with individual contents.

\section{Ambulant}

Many locative projects dispense with screen-based representation or gallery presentation as the primary site of the work and instead involve walking and moving about. Where the focus is on mediated experience specific to a certain location or locations, this category is likely to be a natural companion or correlate of geo-annotation projects, rather than an option exclusive of them.

Interpretive, Explanatory. Some projects involve a journey that is informative responding to and illustrating features of the natural or human-made environment. Here the media is about that place, describing or elaborating it. The simplest cases involve following a path, such as in a heritage trail, where the user is guided in their journey by, say, an audio monologue. Otherwise, a project may enable users to find their own path through a set of predetermined possibilities, moving through an area that has been mapped out and encountering interactive media that correspond to certain locations or objects.

Expressive, Generative. Here the journey is creative and expressive. Audio or video walks, of the kind Janet Cardiff has been creating since the early 1990s, entail a more esoteric encounter with media objects and environment. An ambulant action that engages in computation is .walk, by Wilfried Houjebek (the Netherlands), which uses simple commands (in an analogue of computer code) to prompt a series of movements by participants, who follow algorithmic patterns around the city and who alter those algorithms and paths by exchanging numerical data with the other participants they encounter. walk is generative in the sense that the consistent application of a simple algorithm continually shuffles the movements of participants with open and unpredictable results. In creating an intimate and direct relationship between bodies and code, it also shifts the focus from mapping or visualization to performativity-enabling normally hidden operations to be not only brought into view but also performed:

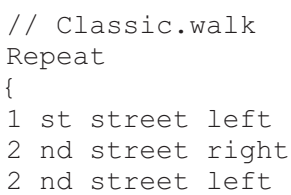

Social, Relational. Radio Ballet (Germany) and Park Bench TV (U.K.) involve interventions in which participants are invited to use public space in a nonobvious way, one involving a flash mobcum-ballet in a train station (Fig. 3); the other, community wireless and media at a park bench. They each exploit the discontinuity between urban space and the invisible layer of media floating above it to juxtapose incongruous actions or behavior. The intersection of the digital and the geographic brings into proximity different kinds of incommensurable space. The engineering challenge of vertical handover, moving seamlessly between wireless networks of varying resolution and latency, finds an analogue in negotiating seams between overlapping and discontinuous social milieu. This affords an opportunity to intervene and to play. Instead of interpreting or embellishing a location, projects such as Radio Ballet and Park Bench TV present something that is more relational, attempting not to resolve the discontinuities but to hold them open, enabling us to stand momentarily outside the everyday. Here locative art is not to do with simple representation, nor placement of digital objects nor simply moving about. It is instead an intervention that is simultaneously spatial and social.

\section{DECONSTRUCTING THE GRID: DIS-LOCATIVE ARTS}

Locative art's focus on networking, authoring and accessing creative content within the environment offers the chance to take art out of the galleries and off the screen. This hope needs to be tempered by an awareness that, in place of the richness of embodied experience of the world, many projects offer the challenge of roaming the environment while squinting at a tiny screen and clunky menu, separated from the world by a barrier of bad usability. What is more, some locative projects may be "of the world" but are not "in the world": their final form is on-line or gallery based, rather than experienced via mobile devices or "old media" such as stickers.

In an important sense, this is a false distinction, however. First, even if the final form is screen-based, the process through which the work is produced is commonly located within the rural or urban environment, typically in the form of workshops involving a small number of practitioners. More importantly, to the extent that the focus is on the dynamic relation between data space (or database) and world, it is incidental where the final representation is sited.

The nature of this relationship between database and world is of greater consequence than simply the question of whether the project is sited "in the 
world," on-line or in a museum or gallery. One issue that quickly becomes apparent is the reliance in locative arts on the clinical precision of digital tracking and the emphasis on point-to-point correspondence [9]. Projects that draw not only on cartographic tools but also on metaphors of mapping tend to aim for a one-toone correspondence between world and image, between the movements of participants and their screen-based representation. Likewise many geo-annotation projects seek a determinate placing or fixing of position, wherein location is unambiguously designated or assigned. In most cases ambiguity-or disruption of mechanical precision-arises only in the negotiation of land features and the resolution or granularity of technical hardware.

Furthermore, locative media often assumes a reductive understanding of spatiality. It encounters the fabric of space-time via an abstract coordinate system, betraying its indebtedness to cartography and GIS, in which location is reduced to a set of geographic coordinates or a wireless cell. In this respect the parallel between locative art and the work of Richard Long gains further resonance with the intervention of Bill Drummond, in which he drew $\mathrm{x} / \mathrm{y}$ coordinates on one of Long's photographs before cutting out the pieces one by one. These pieces are now circulating in the hands of a thousand new collectors. Locative media's understanding of location often seems to share more in common with that of Drummond than of Long, its transcendent frame of reference and Cartesian space much like the grid marked by
Drummond on Long's photograph [10]. Locative art's condition of possibility is a prior abstraction, and as a consequence its emphasis on location is accompanied by a distancing from embodiment, physicality and context, which-within such a reductive understanding of spatialitybecome a mere residue of the coordinate system.

One project that moves us toward an engagement in the perspectival and embodied is also in many ways the direct precursor to locative art. From its initiation in 1992, through its many contemporary iterations, Masaki Fujihata's Field-Works (Color Plate E) shows how nuance and hidden depth can emerge through the creative use of a technology designed to impose a rigid cartographic grid upon the world, going beyond simple documentation to open a rich space of contextual and aesthetic meaning. Through a juxtaposition of location data captured by GPS and moving images captured by video, it aims to articulate local narratives, while also excavating a sense of parallelism in the universe on a human scale. Field-Works stretches and pulls at the coordinate system, in the same way that dancers play with shifting the body's center of gravity to create a kind of distortion in the fabric of space-time. This is firstly achieved simply by introducing multiple viewpoints, and secondly by using a camera-mounted gyroscope to translate even the intimate movements of the physical gaze as a part of the resulting work, the video frame-viewed moving along a GPS trace-shaking and turning to correspond to unsteady motion of the camera during filming. In earlier ver-
Fig. 3. LIGNA, Radio Ballet Leipzig, 2003. (Photo @ Eiko Grimberg)

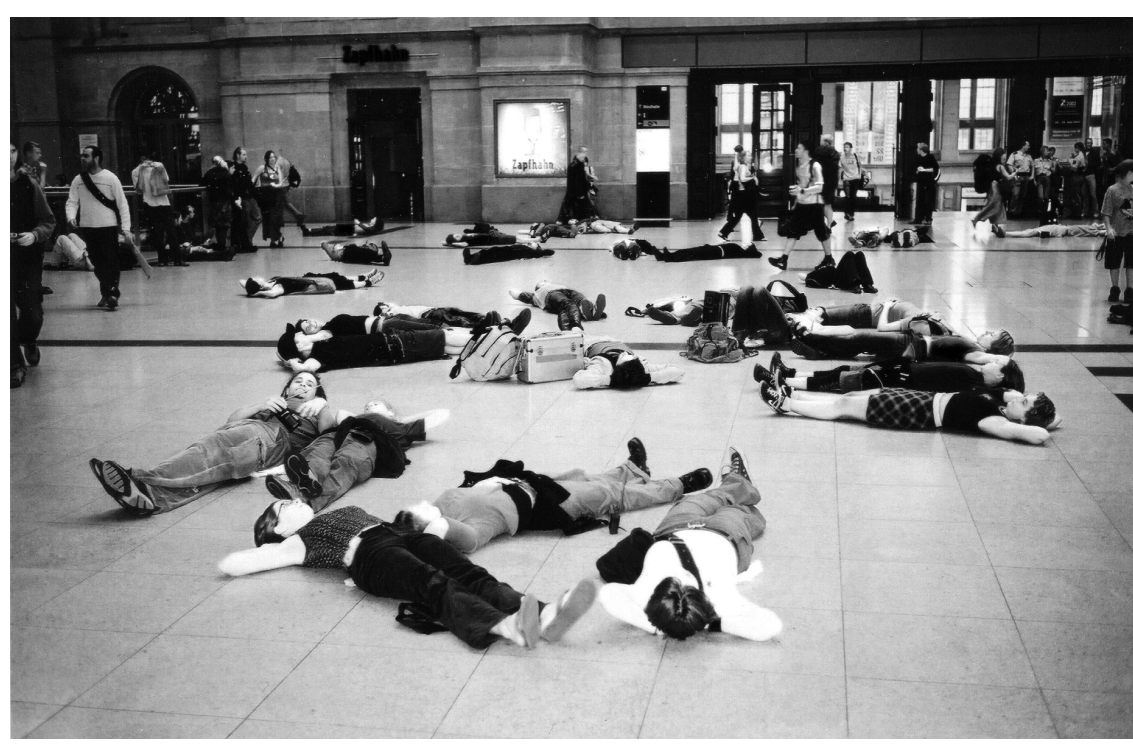

sions of the project, a subversion of the Cartesian grid was effected by representing the physical terrain as a function of the speed at which it is encountered; in one iteration the shape of Mount Fuji became distorted, the same slope shown to be longer when going up than when going down.

In Choreography of Everyday Movement, Teri Rueb (U.S.A.) works with classically trained dancers to explore the poetics of the urban body, as well as the distance between the world and its representation. It too incorporates GPS traces in the final gallery-based representation, but here they are inscribed in sheets of Perspex, which are then layered to create a kind of Rorschach image. The longitude/latitude coordinates are deliberately removed-"The performer is only visible as an ant-like dot crawling across the screen. Movement and physical presence are reduced to the most basic abstraction" [11]. Here we are reminded of Lev Manovich's identification of radar as that which epitomizes the use of linear perspective to map and identify objects and spaces: "Radar is the best example of the rationalization of sight in the twentieth century.... [A] radar operator sees a screen, a dark field with a few bright spots. Here the function of visual nominalism ... is isolated and abstracted" [12]. Just as radar can be said to clarify and condense the function of modern visual surveillance technologies, so Rueb takes the real-time abstraction of movement to an extreme at which its limit is revealed, the cartographic function left bare. Choreography illustrates how-as a databased form-locative art brings the coordinate system itself into the frame as the material upon which it works.

Achieving a similar effect from a very different approach is Location, Location, Location (2004), by Pete Gomes (U.K.). This saw Gomes walking and drawing within a 1-km-square area in London, taking GPS readings and annotating the urban environment in chalk. In some cases Gomes drew numerical readings of position or time at sites where he encountered objects or events; in other cases chalk lines following longitude or latitude were drawn on, and in some cases even through, buildings. This project, and related works by Gomes such as SE8 v1.0 (2004), inscribes the cartographic grid on the city, making an idealized Cartesian space manifest. It does so, however, only to then reassert the transient, material and everyday. The drawings are temporary, quickly washed away by rain. In the impossibility of continuing a true 


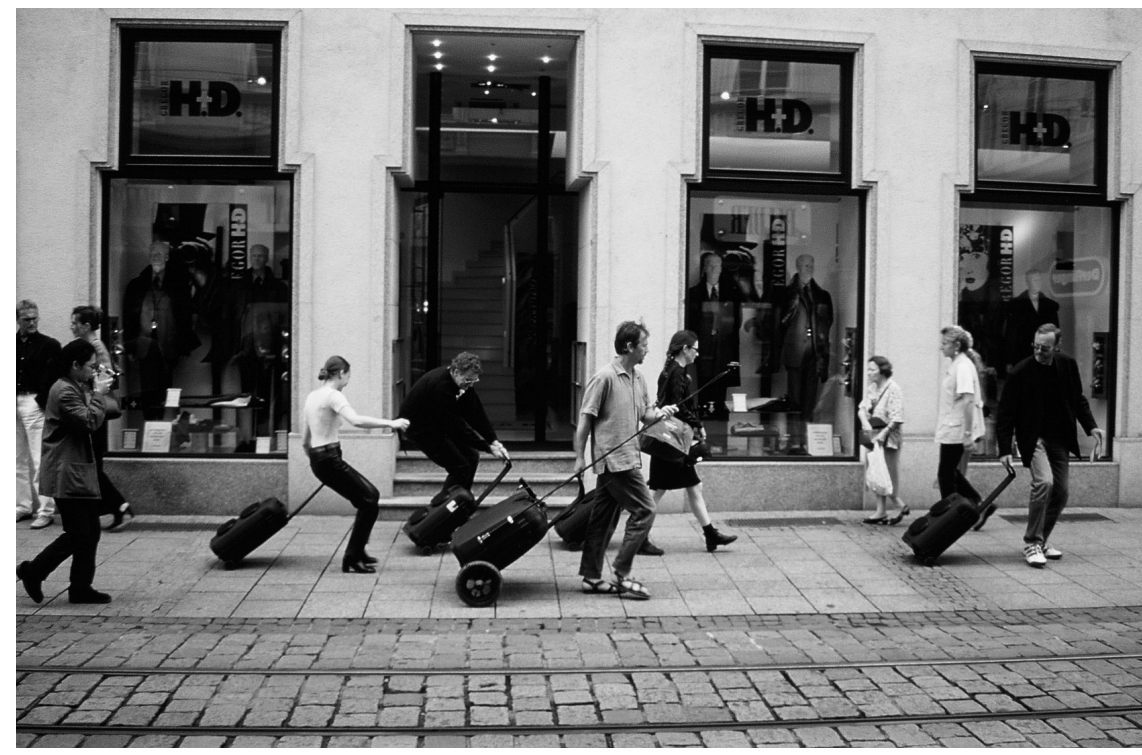

Fig. 4. Iain Mott, Sound Mapping, Linz, 1998. (Photo @ Iain Mott)

grid line at street level, the project highlights the opacity of bricks, mortar and lived space. Moreover, in the way it is experienced by an audience moving through the city, it foregrounds not the omnipresent perspective of satellites circling overhead but a partial and incomplete perspective at ground level, bringing cartography down to earth [13].

Other projects shift the focus away from positioning toward proximity and relationality. In Hlemmur in $C$, by Pall Thayer (Iceland), two taxis equipped with GPS and their base at the Hlemmur bus terminal in Reykjavik are each represented with a middle $\mathrm{C}$ note. While the sound attributed to the base remains constant, the pitch associated with the taxis varies according to their distance from the base, creating instability in the tone. This piece also involves a visual mapping component, but is most interesting in the way in which proximity is registered as dynamic tension in the sound, a strange and disconcerting auditory space.

Sound Mapping, by Iain Mott, is an installation in which participants realize a composition by wheeling four movement-sensitive suitcases within a public place (Fig. 4). Four of the cases contain odometers measuring wheel rotation in both directions as well as two gyroscopes measuring tilt and azimuth, and they are linked by data radio transmitters to a fifth case equipped with GPS. While much work with GPS is limited by its low resolution-the nuance of embodied experience exchanged for a blunt on/off switch every few meters-Sound Mapping produces music in response to nearby architectural features, subtle movements and gestures, and the absolute and relative movements of the participants.

Biomapping, by Christian Nold (U.K.), measures galvanic skin response-using a customized device of the kind used in lie-detector tests, combined with GPSto record anxiety and stress levels of participants as they move through the city. Here the body is brought into the equation only to be abstracted and left behind. Nold works with readings plotted onto a map in the same way other projects record a visual trace of movement, the composite images mirroring the way Amsterdam RealTime reveals the idiosyncrasy of how urban space is used. There is a reverse movement in the way that people respond to readings-their own or those of previous participants-this shaping their movement through the city. From the perspective of the user roaming the city, it prizes open a space between the physical environment, networks and the body and offers a different way of encountering the city, where the low-cost, DIY aesthetic of the Biomapping device becomes more significant than the accuracy of its representation of physiological data.

\section{OTHER GEOMETRIES: RELATIONAL AND SOCIAL}

One trajectory that may be discerned within locative arts-implicit in the taxonomy above-runs from realism and documentation (conventional maps, city guides) to expression (digital graffiti, ambient narrative) to the collaborative and social (collaborative maps, social authoring). In broad terms this mirrors a simi- lar trajectory in locative media generally, identified by Ben Russell among others, from the spatial to the social [14]. And it may be situated alongside a broader blurring of the distinction between art and the social today, which marks a departure from conventional understandings of the place of the artist in Western culture and in particular the post-Enlightenment understanding of the artist as apart from society.

An emphasis on the social is likewise found in Nicolas Bourriaud's understanding of relational art: "an art taking as its theoretical horizon the realm of human interactions and its social context, rather than the assertion of an independent and private symbolic space" [15]. The kind of relationality involved in projects such as Hlemmur in Cand Body Mapping is primarily geometric and spatial. Another kind of "relationality" arises through the overlapping of different kinds of mapping - geographical maps, social network maps, node maps, etc. Something a little closer to Bourriaud's understanding may be seen in locativeart projects that explicitly engage an audience in a social space or process. They tend to offer something different from the gallery-centric, white-cube sociality proposed by Bourriaud, for where relational-art projects tend to be staged and exceptional, locative arts are more often implicated in the everyday, even if only in their willingness to address nonart contexts.

Park Bench TV, by Gomes, involved a park bench with free Wi-Fi access, plus a chat forum and local TV channel to which anyone with a wireless-enabled laptop had access. The bench served as a physical metaphor for the wireless node and a focal point for local content, but it also brought users into physical proximity and-through the layering or coincidence of different types of location (inner-city park, bench, Internet chat room)-produced an uncertain and incongruous social space [16]. This project also prefigures a wider trend toward free networks becoming portals to a local environment or community-as championed by the collective île Sans Fil in Montreal, for example-rather than just access points to an undifferentiated bandwidth. In another project, Life: A User's Manual, Michelle Teran walks the streets equipped with a scanner and a monitor-in one iteration wheeling them along in a shopping cart-picking up feeds from closed-circuit TV cameras she passes, which are visible on her mobile screen. Her solitary intervention serves 
as a metaphor for the alienation of the surveilled subject, but in intercepting the signal she also creates a counter-site and invites people in: audience, passersby and on occasion employees of the companies operating the cameras. Radio Ballet, described by the group as an "exercise in unnecessary loitering," involves a choreographed and orchestrated performance guided by audio broadcast over a free network. It creates a happening or event at variance with the everyday, functional use of space, and in so doing brings the social norms that govern our use of public space into view. These projects offer a view of locative art as something more than spatial representation. Indeed, they fall outside a narrow definition of locative art or locative media. And yet they illustrate how spaces that are both social and other can be opened at the interface of communication, location and the body.

Whereas "mixed reality" posits the virtual and physical as layered or intersecting, these projects suggest that something else can be produced in between. In locative-media projects we find a fold between virtual and physical, data space and geographical space. In some cases, such as Houjebek's generative walk or Gomes's park bench, these folds do not just mix realities but produce a reality of their own. They might in this sense be said to be counter-sites and-like Foucault's "heterotopias," or "other" places-to place all other sites into question [17]. This might be metaphoric as much as literal. We might, for example, ask how the intensity of luminescence in Amsterdam RealTime or the trace of embodiment in Biomapping might be said to constitute a heterotopic image, an image of an other place, rather than a representation of the real. Likewise, we might ask of geoannotation projects how they open an "other" space, which is not the same as providing more sophisticated interpretive tools.

The straightforward geo-annotation of space-placing data in geographical space-can be seen as an instance of what Deleuze and Guattari have termed emplacement, which they distinguish from haecceities, or "concrete individuations that have a status of their own and direct the metamorphosis of things and subjects" [18]. These have the kind of individuality we find in seasons or dates, as opposed to subjects or things, and "consist entirely of relations of movement and rest between molecules or particles, capacities to affect and be affected" [19]. When locative media hides behind the console of positioning systems, an ab- stract mode of individuation results. For locative art to exceed the sterile precision of its own axiomatic system, it needs to act upon or through material bodies and substances, engage in the ambiguity, dirt, sweat and smells of the world, and acknowledge "the importance of rain, hail, wind, pestilential air, or air polluted by noxious particles, favourable conditions for these transports" [20]. Locative arts can then come to be seen not as distanced from the world but as offering a potential for transformation and engagement, opening up other places, their contents circulating through locationaware networks, producing a field of relations and affects.

\section{References and Notes}

1. Gilles Deleuze and Felix Guattari, A Thousand Plateaus, Brian Massumi, trans., Minneapolis (University of Minnesota Press, 1987) p. 316.

2. Chang and Goodman have argued that location can be viewed not as canvas but as medium ("Asphal Games: Enacting Place through Locative Media," in D. Hemment [ed.], Leonardo Electronic Almanac, Spe cial Issue on Locative Media, 2006).

3. "Locative art" is here understood as those areas of locative media that are predominantly arts-based. Much interesting work happens on the boundary, and this term is intended to contribute to discourse on locative media, not to set up any kind of opposition.

4. Location and context are central to the mobile and wireless experience. A wireless or mobile art might also be concerned with, say, the potential of might also be concerned with, say, the potential of
interfaces unfettered by wires and cables for performance or interaction.

5. In particular between the influential Karosta workshop organized by RIXC in July 2003 and the Mobile Connections exhibition at Futuresonic in May 2004.

6. The term "locative media" was coined by Karlis Kalnins (Canada) in 2003.

7. Thanks to Ben Russell for his comments on the Karosta images.

8. PLAN workshop in October 2005, project documentation, http://www.open-plan.org.

9. The issue is not the accuracy or granularity of the technical system employed. Most tracking systems are anything but precise, as the Karosta images illustrate. Different systems have different granularity or resolution, ranging from sensor networks (high) to cellbased location data from mobile phones (low), and this will vary depending on the context: GPS, for example, is unreliable in built-up areas.

10. This view of an endless grid that extends acros the Earth found iconic form in Superstudio's Continuous Monument project (1969). More recently, Andrew Wilson from Blink has argued, "Wirelessness not a grid laid across the world. Wirelessness is clusters and gaps." Ultrasound conference, 2004, http:// www.ultrasound.ws/archive/2004/index html.

11. Teri Rueb, http://www.terirueb.net/.

12. Lev Manovich, "Modern Surveillance Machines: Perspective, Radar, 3-D Computer Graphics, and Computer Vision," in CTRL [SPACE]: Rhetorics of Surveillance from Bentham to Big Brother (ZKM, Karlsruhe/The MIT Press, Cambridge, Massachusetts, 2002) p. 386.

13. Pete Gomes, "Signage for Invisibility," in Marc Tuters and Rasa Smite, eds., Acoustic Space: Trans Cut tural Mapping (Riga: The Center for New Media Cul- ture RICX, 2004) pp. 175-177. Also available on-line, http://www.locative.net/tcmreader/index.php?loc arts;gomes.

14. Ben Russell (U.K.) is author of Headmap Manifesto (1999, http://www.headmap.org/headmap.pdf), and one of the founders of the Locative Media Lab (http://www.locative.net), which also included Marc Tuters (Canada) and others.

15. Nicolas Bourriaud, Relational Aesthetics (Paris: Les Presses du Reel, 2002).

16. A similar approach has been taken more recently by Anab Jain (India/U.K.) with her work Yellow Chair (2005), http://anab.in/yellowimages.html.

17. M. Foucault, Of Other Spaces. Diacritics, Spring 1986, pp. 22-27.

18. Gilles Deleuze and Felix Guattari, A Thousand Plateaus, Brian Massumi, trans. (Minneapolis: University of Minnesota Press, 1987) p. 261

19. Ibid.

20. Ibid.

\section{URLs}

Field-Works, by Masaki Fujihata, http://www.fieldworks.net/.

Teri Rueb, http://www.terirueb.net.

Stefan Schemat, http://www.schemat.de/.

Sound Mapping by Iain Mott, http://www.reverber ant.com/.

Amsterdam RealTime by Ester Polak, http://real time.waag.org/.

Locative Media Workshop at Karosta, Latvia, http:// locative.x-i.net/.

RIXC, http://rixc.lv/.

Distance Made Good by Jen Hamilton and Jen Southern, http://www.theportable.tv/dmg/.

GPS Drawing, http://www.gpsdrawing.com/.

Myriorama by AmbientTV.NET (UK), http://www. ambienttv.net/4/myriorama/.

Location, Location, Location (2004) by Pete Gomes, http://www.mutantfilm.com/wireless/. See also http://www.locative.net/tcmreader.

Trace Encounters by Bradford Paley, http://www. traceencounters.org/.

Familiar Strangers by Eric Paulos and Elizabeth Goodman, http://berkelev.intel-research.net/pau los/research/familiarstranger.

Geograffiti, http://www.gpster.net/geograffiti.html.

GeoNotes, http://geonotes.sics.se/.

InterUrban by Jeff Knowlton, Naomi Spellman and Jeremy Hight, http://interurban.34n118w.net/.

Blast Theory, http://www.blasttheory.co.uk/.

Mixed Reality Lab, http://www.mrl.nott.ac.uk/.

(area)code by Jen Southern and centrifugalforces, http://www.areacode.org.uk/.

[murmur], http://murmurtoronto.ca/.

Yellow Arrow, http://yellowarrow.org.

Urban Tapestries, http://urbantapestries.net/.

Mobile Bristol, http://www.mobilebristol.com.

.walk by Wilfried Houjebek, http://www.socialfiction. org/dotwalk/.

Radio Ballet by Radio Ligna, http://www.okcentrum.at/english/ausstellungen/open house/ ligna.html.

Park Bench TV by Pete Gomes, http://www.mutantfilm.com/parkbenchtv/. 
Hlemmur in C by Pall Thayer, http://130.208.220. 190/hlemmC/.

Biomapping by Christian Nold, http://www.bio mapping.net.

île Sans Fil (Wireless Island), http://www.ilesans fil.org.

Life: a User's Manual by Michelle Teran, http:// www ubermatic.org/life/.

Web sites accessed December 2005.
Drew Hemment is Director of Future Every thing, a nonprofit company responsible for Futuresonic International Festival; AHRC Re search Fellow in Creative Technologies, University of Salford; and Project Investigator in the Pervasive and Locative Arts Network (PLAN). He is currently working on the in terdisciplinary arts-based research project Loca: Location Oriented Critical Arts. Projects include Loca (2003-present), Futuresonic (1995-present), Low Grade (2005), Mobile Connections (2004), FutureDJ(2004), Turntable Re:mix (2004), Migrations (20022003), Blacktronica (2002), Sensurround (2001-2002), BrokenChannel (2001) and SenseSonic (2000). Hemment was involved in early U.K. electronic dance culture as a DJ and event organizer. He completed an MA at the University of Warwick and a Ph.D. at the University of Lancaster.

\section{Leonardo Celebrates Leonardo da Vinci Special Section of Leonardo, 2007-2008}

In celebration of Leonardo journal's 40th anniversary, we are calling for essays related to Leonardo da Vinci and his concerns regarding the relationship between art and science. We are interested in submissions in which Leonardo's own concerns serve as a springboard for looking toward the present. What, building upon Leonardo's ways of thinking, can artists and scientists tell each other today? We also seek original accounts of his visual art, of his achievements as a proto-scientist and of the relation between his concerns with science and with visual art.

Recommended length: 2,500-3,500 words.

Illustrations per essay: 5-8 black-and-white images; possibly one color image.

Prospective authors are encouraged to review the Leonardo Author Guidelines on the Web: www.leonardo.info. (Follow the links: Publications, Information for Authors, Leonardo Print Journals, Editorial and Illustration Guidelines.)

All papers will be peer-reviewed prior to acceptance for publication.

Submissions deadline: 15 January 2007.

Please send inquiries and submissions to Guest Editor David Carrier:<david.carrier@cwru.edu>. 


\section{Leonardo Journals and Books Available in Bookstores}

Leonardo journals are available through subscription, but they can also be purchased in selected bookstores. Here is a partial list of bookstores that carry Leonardo and Leonardo Music Journal (LMJ).

If you are aware of a local bookstore that you think would be interested in carrying Leonardo, please send us contact information for the bookstore and we will have MIT Press follow up (send info to $<$ isast@leonardo.info $>$ ).

Leonardo books and journals can be ordered on-line through $<$ http://mitpress.mit.edu $>$. Leonardo Books can also be ordered through local bookstores or through on-line booksellers.

U.S. Bookstores (Leonardo):

Berkeley Art Museum Store 2625 Durant Ave.

Berkeley, CA 94720

The Bookery

Dewitt Mall

215 N. Cayuga St.

Ithaca, NY 14850

Builders Booksource

1817 Fourth St.

Berkeley, CA 94710

City Lights Bookstore

261 Columbus Ave.

San Francisco, CA 94133

Cody's Books

2 Stockton St

San Francisco, CA 94108

Eyebeam Bookstore

540 W 21st St.

New York, NY 10011

Franz Bader Gallery

1911 Eye St. NW

Washington, D.C. 20006

$\mathrm{J} \& \mathrm{~S}$ Broadway News

204 Broadway Ave. E

Seattle, WA 98102

$\mathrm{J} \& \mathrm{~S}$ Fremont News

3416 Fremont Ave. N

Seattle, WA 98103
Micawber Books

114 Nassau St.

Princeton, NJ 08542

MIT Press Bookstore

292 Main St.

Cambridge, MA 02142

News Express

1803 Connecticut Ave.

Washington, D.C. 20009

Newsland

2112 Central SE

Albuquerque, NM 87106

Skylight Books

1818 North Vermont

Los Angeles, CA 90027

St. Mark's Bookshop

31 Third Ave.

New York, NY 10003

Stanford Bookstore Dist. Center

8424 Central Ave.

Newark, CA 94560

University of Minnesota Bookstores

231 Pillsbury Dr., SE

Minneapolis, MN 55455

Canadian Bookstores (Leonardo):

Librairie Olivieri

5200 Gatineau

Montreal PQ H3T 1W9

Canada
Other Non-U.S. Bookstores (Leonardo):

La Central Libreria del Raval

Elisabets, 6

08001 Barcelona

Spain

Laie-CCCB

Montalegre, 5

08001 Barcelona

Spain

Stichting V2 Institute Unstable Media c/o Hans Beekmans

Eendrachtsstraat 10

3012 Xl Rotterdam

The Netherlands

\section{U.S. Bookstores (LMJ):}

Cody's Books

2 Stockton St

San Francisco, CA 94108

Newsland

2112 Central SE

Albuquerque, NM 87106

Yankee Book Peddler

999 Maple St.

Contoocook, NH 03229

Non-U.S. Bookstores (LMJ):

Stichting V2 Institute Unstable Media PO Box 19049

3001 BA Rotterdam

The Netherlands 